http://jmscr.igmpublication.org/home/ ISSN (e)-2347-176x ISSN (p) 2455-0450

crossref DOI: https://dx.doi.org/10.18535/jmscr/v8i3.17

\title{
Evaluate Efficacy of Autologous Platelet Rich Plasma Injection versus Conservative Modalities in Treatment of Chronic Tendenopathies
}

\author{
Authors \\ Dr Dinesh Kumar ${ }^{1}$, Dr Utkrisht Mandot ${ }^{2}$, Dr Ramvilas Nag ${ }^{3}$, \\ Dr Manoj Kumar Dwivedi ${ }^{4}$ \\ ${ }^{1}$ M.S ortho, Assistant Professor, Department Of Orthopedic, Shyam Shah Medical College Rewa, M.P \\ ${ }^{2}$ M.S Ortho, Assistant Professor, Ananta Institute of Medical Science Udaipur, Rajasthan \\ ${ }^{3}$ M.S Ortho, Navkar Orthopedic Hospital, Mumbai \\ ${ }^{4}$ D.N.B Ortho, Senior Resident Department of Orthopedics, Shyam Shah Medical College Rewa, M.P \\ *Corresponding Author \\ Dr Utkrisht Mandot
}

\begin{abstract}
Introduction: Tendinopathies are primarily degenerative condition with the absence of inflammatory cells in and around the lesion. A variety of treatment modalities like eccentric exercises, shock-wave therapy have been tried in the past but none of it seems to be promising. Recently, platelet-rich plasma $(P R P)$ addresses several aspects of the healing process and enhances tendon healing.

Materials and Methods: Prospective cohort study consisting of eighty patients with chronic tendinopathies (lateral and medial epicondilitis, plantar fasciitis, achilles tendinitis) were divided into two groups viz. Group A and group B of forty patients each. Group A received autologous platelet rich plasma (PRP) injection and group B received conservative management. Patients were followed up at 6th, 12th and 24th weeks after intervention and analyzed by Visual Analogue Scale (VAS).

Results: Mean VAS score decreased from 5.85 at start to 3.30 at 24th week follow-up in group A and from 5.40 at start to 5.30 at 24th week follow-up in group B. Statistically significant decrease in mean VAS scores have been observed in group A as compared to group B.

Conclusion: PRP is effective in short-term treatment of chronic tendenopathies. Lateral epicondilitis responds most to PRP whereas planter fasciitis responds least of all the tendenopathies studied.

Keywords: Platelet rich plasma, Lateral epicondilitis, chronic tendenopathy, plantar fasciitis, achilles tendinitis.
\end{abstract}

\section{Introduction}

Tendinopathies are primarily degenerative condition with the absence of inflammatory cells in and around the lesion. Hence, treatment with anti-inflammatory drugs has showed a little benefit in controlled trials. Molecular mechanisms underlying the cause and progression of tendinopathy have begun to be elucidated in recent years.

A variety of treatment modalities like eccentric exercises, shock-wave therapy have been tried in the past but these proved to be futile exercise. Topical nitroglycerin patches have been shown to improve outcomes in double-blinded randomized 
controlled trials, possibly by enhancing collagen synthesis ${ }^{1}$; Sclerosant injections have been shown to give short-term benefit ${ }^{2}$. Recently, locally injected growth factors have been tried to improve tendon healing and have gained the interest of researchers around the world. Platelet-rich plasma (PRP) addresses several aspects of the healing process including cell proliferation and tissue matrix regeneration, inflammation, nociception, infection, and hemostasis and thus enhancing tendon healing.

\section{Materials and Methods}

Prospective cohort study conducted in the department of Orthopaedics, Institute of Medical Sciences, Banaras Hindu University, Varanasi from August 2013 to July 2015 in collaboration with blood bank. Eighty patients with chronic tendinopathies were divided into two groups viz. Group A and group B randomly using simple number randomizing method. Group A comprised of forty patients who received autologous platelet rich plasma (PRP) injection and group B comprising of forty patients who received conservative management (physiotherapy and placebo). Both groups were similar in baseline characteristics (Table 1).

\section{Inclusion Criteria}

1. Men and women between age group of 18 to 75 years of age.

2. Tendinopathy involving medial (golfers elbow) and lateral (tennis elbow) aspect of elbow, plantar fasciitis and achilles tendinitis for a period greater than six months that has not resolved with conventional treatment modalities (oral medication, physiotherapeutic modalities and eccentric exercises).

\section{Exclusion Criteria}

1. Sensory and neurologic complaints affecting the specified regions

2. Coagulation disorders, platelet disorders Pregnancy or major systemic illness such as diabetes mellitus, rheumatoid arthritis, fibromyalgia, autoimmune disorders

3. Any condition that required strict anti platelet or anticoagulation therapy.

\section{Diagnostic Criteria}

1. Patient with documented pain upon palpation over the tendon insertion and pain with the resisted activation of the tendon.

2. Ultrasonographic findings consistent with tendinopathy i.e. Fluid in the tendon sheath, thickening or thinning of the tendon, irregularity of the tendon borders, absence of the normal fibrillary appearance and focal areas of low echogenicity with a background of intrinsic tendinopathy.

\section{PRP Preparation}

$300 \mathrm{cc}$ of patients own blood was collected in quadrupled bag prefilled with 50cc anticoagulant (CPD-A). These bags were then centrifuged at the rate of $2450 \mathrm{rpm}$ for the duration of 3 minutes (slow spin). Blood components got separated into three layers from top to below as follows: plasma, buffy coat (leukocytes \& platelets), red blood cells (RBC). Buffy coat and plasma is separated and is again centrifuged at $3880 \mathrm{rpm}$ for the duration of 5 minutes (fast spin) and concentrate of platelets is thus obtained. Leucocyte filter was not used in our case and the PRP obtained was type 2A as per mishra classification ${ }^{3}$.

\section{Method of Intervention}

Patients were made to lie down in supine position except in case of achilles tendinitis in which patient is kept in prone position. 2-5cc of PRP was locally injected at the point of maximum tenderness. The affected part was kept immobilized for 15 minutes to check for any adverse reaction; jones compression was applied and remaining packed RBC's was infused to the patients.

\section{Results}

Patients were followed up at $6^{\text {th }}, 12^{\text {th }}$ and $24^{\text {th }}$ weeks after intervention and analyzed by VAS (Visual Analogue Scale) and Likert scale (Table 2). 


\section{Statistical Analysis}

It was done using SPSS Inc., Chicago, IL, version 22.0 for windows. ANOVA test was used to test the significance of difference for quantitative variables and Fisher's chi square test for qualitative variables. A 'p' value less than 0.05 were taken to denote significant difference.

Table 1: Baseline characteristics of the patients in group A and group B

\begin{tabular}{|c|c|c|c|c|}
\hline & & Group A $(n=40)$ & Group B $(n=40)$ & $\mathrm{P}$ value \\
\hline \multicolumn{2}{|l|}{ Age (mean) years } & 34.8 & 37.4 & $\mathrm{P}=0.792$ \\
\hline \multicolumn{2}{|l|}{ Sex (M:F) } & $16: 24$ & $17: 23$ & $\mathrm{P}=0.820$ \\
\hline \multicolumn{2}{|l|}{ Types of } & \multirow{3}{*}{5} & \multirow{3}{*}{6} & \multirow{6}{*}{$P=0.763$} \\
\hline \multirow[b]{5}{*}{ Tendenopathy } & Plantar fascitis & & & \\
\hline & Golfer's elbow & & & \\
\hline & Achilles Tendinitis & \multirow{2}{*}{$\begin{array}{l}7 \\
2\end{array}$} & 8 & \\
\hline & Tennis elbow & & 4 & \\
\hline & & 26 & 22 & \\
\hline Baseline VAS (me & D) & $5.85 \pm 1.46$ & $5.40 \pm 2.08$ & $\mathrm{P}=0.267$ \\
\hline
\end{tabular}

Table 2: Changes in VAS score during follow-up

\begin{tabular}{|l|c|c|c|}
\hline VAS at & Group A $(\mathrm{n}=40)$ & Group B $(\mathrm{n}=40)$ & P value \\
\hline $6^{\text {th }}$ week $($ mean \pm S.D $)$ & $4.50 \pm 1.85$ & $5.15 \pm 1.86$ & 0.122 \\
\hline $12^{\text {th }}$ week $($ mean \pm S.D $)$ & $3.80 \pm 1.96$ & $5.00 \pm 1.63$ & $\mathbf{0 . 0 0 4}$ \\
\hline $24^{\text {th }}$ week $($ mean \pm S.D $)$ & $3.30 \pm 2.00$ & $5.30 \pm 1.78$ & $<\mathbf{0 . 0 0 1}$ \\
\hline
\end{tabular}

Table 3: A. VAS score Changes in patients with Plantar fasciitis

\begin{tabular}{|l|c|c|}
\hline Time interval & VAS $($ mean \pm SD $)$ & 'p' value \\
\hline Pre-injection & $4.40 \pm 0.89$ & - \\
\hline $6^{\text {th }}$ week & $3.20 \pm 1.78$ & 0.070 \\
\hline $12^{\text {th }}$ week & $2.80 \pm 1.09$ & $\mathbf{0 . 0 1 6}$ \\
\hline $24^{\text {th }}$ week & $2.80 \pm 1.09$ & $\mathbf{0 . 0 1 6}$ \\
\hline
\end{tabular}

B. VAS score Changes in patients with Tennis elbow

\begin{tabular}{|l|c|c|}
\hline Time interval & VAS $($ mean \pm SD) & 'p' value \\
\hline Pre-injection & $5.77 \pm 1.42$ & - \\
\hline $6^{\text {th }}$ week & $4.08 \pm 1.64$ & $<\mathbf{0 . 0 0 1}$ \\
\hline $12^{\text {th }}$ week & $3.08 \pm 1.52$ & $<\mathbf{0 . 0 0 1}$ \\
\hline $24^{\text {th }}$ week & $2.31 \pm 1.08$ & $<\mathbf{0 . 0 0 1}$ \\
\hline
\end{tabular}

\section{Discussion}

Chronic tendinopathies are the conditions that cause significant pain and disability for the duration of more than six months. It can be in form of tennis elbow, golfer's elbow, plantar fasciitis, achilles tendinitis. It is characterized by gradual onset of stiffness in the tendon, activityrelated pain, diminished function, localized swelling and palpable crepitations ${ }^{4,5}$. Clinical assessment remains the cornerstone in appropriate diagnosis and management of tendinopathy ${ }^{6}$. US and/or MRI are useful for confirming the diagnosis in doubtful cases but these imaging techniques are not recommended for monitoring treatment ${ }^{7}$.

Various modalities of treatment are used in tendenopathies viz. eccentric stretching exercises, analgesics, steroids, extra-corporeal shock wave therapy, ultrasonic therapy, silicon heel pads, orthotic devices, splints and casts. Of these commonly used are physical therapy and corticosteroid injections. Corticosteroids have a high failure rates as intratendinous injection leads to permanent adverse changes within the structure of tendon and patients tend to overuse the affected part after injection as a result of direct pain relief ${ }^{8}$. 
Platelet-rich plasma (PRP) is an autologous biologic derivative that consists supraphysiologic levels of platelets ${ }^{9}$. When injected locally, platelets undergo degranulation to release various growth factors with healing properties. The concentrated growth factors within PRP work in cohesion to initiate a healing response within a damaged tendon. This hypothesis has been supported by in vitro data from Klein et al. ${ }^{10}$ Moreover PRP has unique features such as being autologous, anti-infective, and mitogenic, and it is easy to prepare ${ }^{11}$.

Majority of patients were females in fourth decade (34.8 years in group A and 37.4 years in group B). Most common form of tendenopathy encountered in our study was lateral epicondilitis followed by medial epicondilitis, planter fasciitis and achilles tendinitis.

Patients in group A had statistically significant reduction in mean VAS scores i.e. from 5.85 to 3.30 after autologous platelet rich plasma injection at $24^{\text {th }}$ week of follow-up when compared to patients in group B in whom mean VAS scores decreased from 5.40 to 5.30 who were treated by conservative means. Mishra et $a{ }^{12}$ and Peerbooms et al. ${ }^{13}$ made similar observations in patients treated with locally injected PRP and reported reduction in pain compared with the preinjection status.

It was also observed that initially for the first 6 weeks both the groups i.e. group A and group B had similar decrease in VAS scores $(\mathbf{p}=\mathbf{0 . 1 2 2})$ thus it may be believed that PRP releases local growth factors which either promote healing or regeneration. Transforming growth factor $\beta 1$ has been shown to significantly increase type I collagen production from tendon sheath fibroblasts. This same mechanism might be responsible in chronic tendenopathies ${ }^{14}$.

It was observed that decrease in VAS score was maximum in patients with lateral epicondilitis i.e. VAS decreased from 5.77 during pre-injection state to 2.31 at $24^{\text {th }}$ week of follow-up $(\mathbf{p}<\mathbf{0 . 0 0 1})$; least benefit was observed in patients with planter fasciitis in whom VAS decreased from 4.40 during pre-injection state to 2.80 at $24^{\text {th }}$ week of follow-up $(\mathbf{p}<\mathbf{0 . 0 1 6})$. Thus, patients with tennis elbow were benefited maximum from autologous PRP injection amongst the tendenopathies studied (Table 3A and 3B).

\section{Conclusion}

It can be concluded from the above study that local injection of PRP is effective in short-term treatment of chronic tendenopathies. The incidence of lateral epicondilitis is high amongst the different tendenopathies studied. Lateral epicondilitis responds most to PRP whereas planter fasciitis responds least of all the tendenopathies studied.

\section{Limitation of Study}

The study is a short term and prospective nonrandomized study. The study measures only pain amongst different tendenopathies and no radiological evidence was recorded except for the diagnosis.

\section{Reference}

1. Graham Riley. Tendinopathy - from basic science to treatment. Nature Clinical Practice Rheumatology. 2008;4: 82-9.

2. Alfredson $\mathrm{H}$ and Ohberg $\mathrm{L}$ Sclerosing injections to areas of neo-vascularisation reduce pain in chronic Achilles tendinopathy: a double- blind randomised controlled trial. Knee Surg Sports Traumatol Arthrosc. 2005; 13: 338-44.

3. Mishra A, Harmon K, Woodall J, Vieira A. Sports medicine applications of platelet rich plasma. Curr Pharm Biotechnol. 2012;13(7): 1185-95.

4. Andres B.M. and Murrell G.A. Treatment of tendinopathy: what works, what does not, and what is on the horizon. Clinical Orthopaedics and Related Research. 2008;466: 1539-54.

5. Fredberg U, Stengaard-Pedersen K. Chronic tendinopathy tissue pathology, pain mechanisms, and etiology with a 
special focus on inflammation. Scand. J. Med. Sci. Sports. 2008;18(1): 3-15.

6. Cook, J.L., Khan, K.M., Kiss, Z.S., Coleman, B.D. and Griffiths, L. Asymptomatic hypoechoic regions on patellar tendon ultrasound: A 4-year clinical and ultrasound followup of 46 tendons. Scandinavian Journal of Medicine \& Science in Sports. 2001;11: 321-27.

7. Khan, K.M., Forster, B.B., Robinson, J., Cheong, Y., Louis, L., Maclean, L. and Taunton, J.E. Are ultrasound and magnetic resonance imaging of value in assessment of Achilles tendon disorders? A two year prospective study. British Journal of Sports Medicine. 2003;37: 149-53.

8. Smidt N, van der Windt DA, Assendelft WJ, Devillé WL, Korthals-de Bos IB, Bouter LM. Corticosteroid injections, physiotherapy, or a wait-and-see policy for lateral epicondylitis: A randomised controlled trial. Lancet. 2002;359: 65762.

9. Middleton KK, Barro V, Muller B, Terada $\mathrm{S}, \mathrm{Fu} \mathrm{FH}$. Evaluation of the Effects of Platelet-Rich Plasma (PRP) Therapy Involved in the Healing of Sports-Related Soft Tissue Injuries. The Iowa Orthopaedic Journal. 2012;32: 150-63.

10. Klein MB, Yalamanchi N, Pham H, Longaker MT, Chang J. Flexor tendon healing in vitro: Effects of TGF-beta on tendon cell collagen production. $\mathrm{J}$ Hand Surg Am. 2002;27: 615-20.

11. Lacci KM, Dardik A. Platelet-Rich Plasma: Support for Its Use in Wound Healing. The Yale Journal of Biology and Medicine. 2010;83(1): 1-9.

12. Mishra A, Pavelko T. Treatment of chronic elbow tendinosis with buffered platelet-rich plasma. Am J Sports Med. 2006;34: 1774-78.

13. Peerbooms JC, Sluimer J, Bruijn DJ Positive effect of an autologous platelet concentrate in lateral epicondylitis in a double-blind randomized controlled trial: platelet-rich plasma versus corticosteroid injection with a 1-year follow-up. Am J Sports Med. 2010;38: 255-62.

14. Wrotniak M, Bielecki T, Gazdzik T. Current opinion about using the plateletrich gel in orthopaedics and trauma surgery. Orthop Traumatol Rehabil. 2007;9: 227-38. 